\title{
Atividades de vôo de Plebeia saiqui (Holmberg) (Hymenoptera, Apidae, Meliponini) durante o período de postura da rainha e em diapausa
}

\author{
Raquel A. Pick ${ }^{1,2}$ \\ Betina Blochtein ${ }^{1}$
}

\begin{abstract}
Flight activities of Plebeia saiqui (Holmberg) (Hymenoptera, Apidae, Meliponini) during the oviposition period and the diapause. The activities of four colonies of Plebeia saiqui (Holmberg, 1903), of São Francisco de Paula, Rio Grande do Sul, Brazil, were studied from October, 1998 to September, 1999, comparatively during the oviposition period and the diapause. The construction of the cells was monitored by direct observation of the nests. The duration of the diapause period varied from 76 to 168 days. Monthly, the bees that left and entered were counted for 10 minutes, at each hour, during the complete period of flight activity. Influence of meteorological factors on the activities of bees flight was analyzed through simple and multiple regressions. During the oviposition period was found that solar irradiation, temperature and relative humidity had a significant influence on bees flight activity. However, during the diapausa only solar irradiation and temperature played significant influence on bees flight activity. The wind never influenced in a significant way on the flight of the bees.

KEY WORDS. Plebeia, stingless bees, diapause, flight activity, meteorological factors
\end{abstract}

O conhecimento das atividades de vôo dos meliponíneos é essencial para a compreensão dos padrões de forrageamento dessas abelhas, bem como, para a obtenção de subsídios para o uso destes insetos na polinização de cultivos.

Pesquisas sobre atividades de vôo de Meliponini (MiCHENER 2000) relacionadas aos parâmetros meteorológicos foram desenvolvidas com Trigona fulviventris Guérim, 1835 (GILBERT 1973), Trigona carbonaria (Smith, 1854) (HEARD \& HENDRIKZ 1993), Tetragonisca angustula (Latreille, 1811) (IWAMA 1977), Plebeia emerina (Friese, 1900) (KleINERT-GIOVANNINI 1982), Plebeia remota (Holmberg, 1903 ) (IMPERATRIZ-FONSECA et al. 1985), Melipona marginata marginata Lepeletier, 1836 e Melipona marginata obscurior Moure, 1971 (KLEINERT-GIOVANNINI \& IMPERATRIZ-FONSECA 1986) e Melipona bicolor bicolor Lepeletier, 1836 (HILÁRIO et al. 2000).

A sobrevivência das abelhas em baixas temperaturas depende de adaptações bioquímicas e fisiológicas que resultam em períodos de diapausa ou quiescência. A diapausa caracteriza-se pela baixa atividade metabólica, em resposta à sinais ambientais que precedem condições ambientais desfavoráveis. Em contraste com a diapausa, a quiescência não envolve preparação hormonal ou mudanças fisiológicas, e ocorre como conseqüência imediata às condições ambientais adversas (NECHOLS et al. 1999).

1) Faculdade de Biociências, Pontifícia Universidade Católica do Rio Grande do Sul. Avenida Ipiranga 6681, 90619-900 Porto Alegre, Rio Grande do Sul, Brasil.

2) Bolsista da CAPES. 
A percepção da indução da diapausa nos insetos resulta em alterações reconhecidas por sintomas neuroendócrinos, fisiológicos, bioquímicos e comportamentais. A diapausa pode ser caracterizada pela interrupção temporária do desenvolvimento ou da atividade reprodutiva (NECHOLS et al. 1999). Nos insetos sociais, a exemplo de Apis mellifera Linnaeus, 1758, preparações para o inverno envolvem o cessar da atividade reprodutiva e outras mudanças comportamentais que reduzem o desenvolvimento da colônia (KeFuss 1978).

Meliponini que ocorrem em regiões frias, a exemplo de Plebeia julianii Moure, 1962, diminuem ou interrompem as atividades externas e internas da colônia com aproximação do inverno e as recomeçam na primavera (JULIANI 1967).

A diapausa tem sido estudada em insetos designando a supressão do desenvolvimento (TAUber \& TAUber 1976; DENLINGER 1986) e a interrupção na atividade reprodutiva (LEATHER et al. 1993; NECHOLS et al. 1999). Em espécies sociais a interrupção da atividade reprodutiva da rainha e as consequentes alterações comportamentais das operárias foram pouco estudadas (BRIAN \& KELLY 1967; JULIANI 1967; VAN LAERE 1971; IMPERATRIZ-FONSECA \& OLIVEIRA 1976; KEFUSS 1978; KLEINERT-GIOVANNINI 1982; LEATHER et al. 1993; VAN BENTHEM et al. 1995). Neste trabalho adotou-se o termo diapausa, definido por NECHOLS et al. (1999), como o período de interrupção temporária na atividade reprodutiva em resposta às condições ambientais desfavoráveis.

Conhecida como abelha mirim, Plebeia saiqui (Holmberg, 1903) constrói suas colônias em árvores ocas (NOGUEIRA-NETO 1997). Espécie comum em São Francisco de Paula, Rio Grande do Sul, onde foi registrada por WILMS et al. (1997) e WitTmann \& Hoffman (1990), também é encontrada no Paraná e em Santa Catarina (PIRANI \& CORTOPASSI-LAURINO 1993).

O presente trabalho tem como objetivo avaliar as atividades de vôo $P$. saiqui, em ambiente natural, durante os períodos de postura da rainha e de diapausa e a possível influência de fatores meteorológicos.

\section{MATERIAL E MÉTODOS}

\section{Área de estudo}

O estudo foi desenvolvido no Centro de Pesquisas e Conservação da Natureza Pró-Mata (CPCN Pró-Mata/PUCRS), no município de São Francisco de Paula, Rio Grande do Sul $\left(29^{\circ} 27^{\prime}-29^{\circ} 35^{\prime} \mathrm{S}\right.$ e $\left.50^{\circ} 08^{\prime}-50^{\circ} 15^{\prime} \mathrm{W}\right)$ (BERTOLETTI \& TEIXEIRA 1995).

A vegetação predominante é natural, constituída pelas Florestas Ombrófila Mista e Densa e campos. A maior parte da área do CPCN Pró-Mata encontra-se situada entre 600 e 900 m de altitude. Segundo a classificação de Köppen, o clima é considerado subtropical úmido, com regime pluviométrico oscilando entre 1750 e $2500 \mathrm{~mm}$ anuais. A temperatura média anual é de $14,5^{\circ} \mathrm{C}$, sendo as médias anuais mínimas e máximas, respectivamente, $9,9^{\circ} \mathrm{C}$ e $20,3^{\circ} \mathrm{C}$ (IBGE 1986; BERTOLETTI \& TEIXEIRA 1995).

Quatro colônias de P. saiqui (A, B, C e D), do mesmo município, foram transferidas para caixas de madeira $(37 \times 18 \times 28 \mathrm{~cm})$, com $3 \mathrm{~cm}$ de espessura, e 
instaladas em agosto de 1998 no laboratório do CPCN Pró-Mata. Cada colônia foi ligada, através da parede, ao exterior com o auxílio de mangueira plástica (diâmetro de $6 \mathrm{~mm})$.

\section{Observação dos ninhos}

As observações da construção das células de cria e comportamento das abelhas foram realizadas em intervalos de dois a sete dias, através da observação direta dos ninhos (A, B, C, e D), durante os meses de março a setembro de 1999.

As células do favo superior, tanto operculadas quanto em construção, foram monitoradas a fim de determinar o período de diapausa das colônias. Para este procedimento utilizou-se luz fria $(10 \mathrm{~W})$ com filtro vermelho especial, visando minimizar alterações no comportamento de postura da rainha.

\section{Atividades de vôo}

As atividades de vôo das abelhas das colônias A e D foram registradas, de uma a três vezes por mês, durante o período de outubro de 1998 a setembro de 1999 , totalizando 211 observações. Registrou-se a soma das abelhas que saíam e entravam durante 10 minutos a cada hora, do início até o término das atividades de vôo. As contagens foram realizadas com o auxílio de contador manual, nas duas colônias, conforme descrito por OLIVEIRA (1973).

\section{Influência dos parâmetros meteorológicos sobre o vôo}

Os parâmetros meteorológicos (temperatura, umidade relativa, vento e irradiação solar) foram obtidos em intervalos de 30 minutos, das 6:00 às 19:00 h, nos períodos de outubro a dezembro de 1998 e maio a julho de 1999, por meio da estação meteorológica SEBA (versão 1.50, Rel. 009), instalada a aproximadamente $3 \mathrm{Km}$ das colônias.

A influência dos parâmetros meteorológicos sobre as atividades de vôo das abelhas foi analisada utilizando-se regressão simples, para verificar a significância de cada fator isoladamente. Com a regressão múltipla buscou-se relacionar os fatores que contribuíram significativamente para alterações nas atividades de vôo. Os dados foram plotados por dia e de forma agrupada, isto é, sazonal, visando-se comparar os padrões.

\section{RESULTADOS E DISCUSSÃO}

\section{Comportamento das abelhas no interior da colônia}

Durante o período de postura, as abelhas deslocavam-se ativamente e distribuíam-se por todo o ninho. A rainha foi freqüentemente visualizada entre os favos de cria, realizando atividade de postura. As abelhas reagiam rapidamente frente a distúrbios provocados durante o manejo ou devido à invasão por inimigos. Defendiam-se com as mandíbulas e usavam resina contra os intrusos. As construções de potes de alimento, invólucro e células de cria eram freqüentes. Durante as observações verificou-se que as operárias de $P$. saiqui, constroem simultaneamente dois a três favos de cria (Fig. 1).

$\mathrm{Na}$ diapausa as abelhas deslocavam-se lentamente e muitas permaneciam ocultas entre as lâminas do invólucro que recobria os favos e potes de alimento. A 

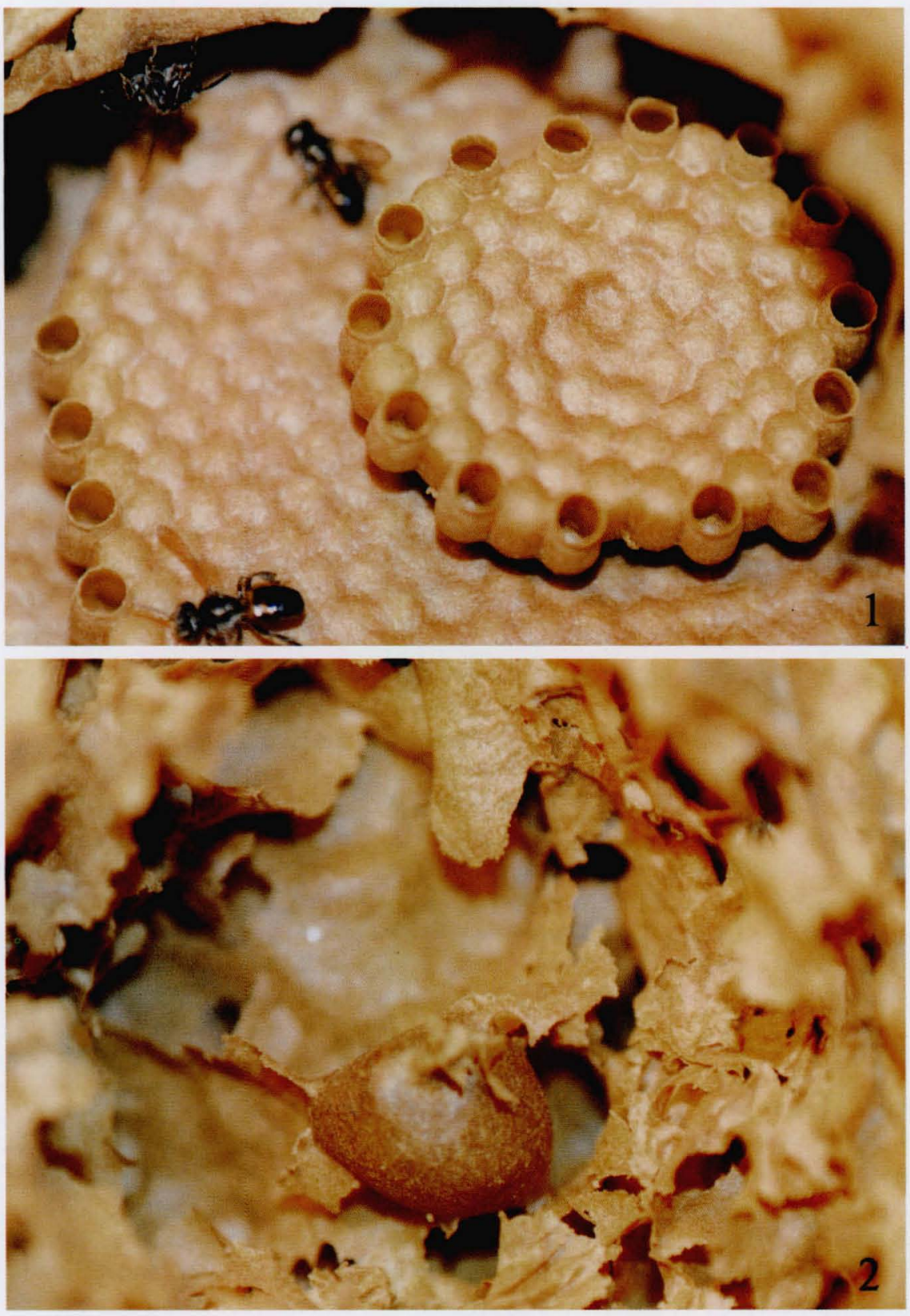

Figs 1-2. (1) Favos de cria de $P$. saiqui. Nas bordas dos dois favos superiores encontram-se células abertas (em construção); (2) pote de mel construído durante o período de diapausa no local anteriormente ocupado pelos favos de cria de $P$. saiqui.

Revta bras. Zool. 19 (3): 827 - 839, 2002 
rainha permanecia entre as lâminas do invólucro. As reações de defesa, a exemplo do uso de resina, foram menos intensas. Após o término da emergência das abelhas das quatro colônias foram construídos de um a quatro potes de mel nos locais anteriormente ocupados por favos de cria (Fig. 2). Novas construções de potes e de invólucro foram lentas e escassas. De modo geral, exceto os processos relacionados à postura da rainha, as demais atividades foram mantidas ainda que de forma reduzida. Esse comportamento coincide com o de Plebeia julianii, que também diminui suas atividades internas e externas nos períodos mais frios (JULIANI 1967). Entretanto, nessa espécie, as abelhas permanecem a maior parte do dia entorpecidas e completamente inativas. Contudo, deve-se levar em consideração que não constróem invólucro (JULIANI 1967) e, por isso, suas colônias estariam mais expostas às variações meteorológicas do que $P$. saiqui.

\section{Atividades de vôo}

Ao longo dos registros das atividades de vôo das abelhas, a irradiação solar mínima para saída foi em torno de $20 \mathrm{~W} / \mathrm{m}^{2}$ (Tab. I) e a maior intensidade de vôo ocorreu a partir de $300 \mathrm{~W} / \mathrm{m}^{2}$ (Fig. 3). HEARD \& HENDRIKZ (1993), em estudos desenvolvidos na Austrália com $T$. carbonaria, verificaram que não ocorre atividade de vôo com irradiação solar abaixo de $15 \mathrm{~W} / \mathrm{m}^{2}$.

Tabela I. Valores mínimos e máximos dos fatores meteorológicos registrados durante as observações das atividades de vôo de $P$. saiqui, no período de outubro de 1998 a setembro de 1999.

\begin{tabular}{lcccc}
\hline \multicolumn{1}{r}{ Periodo } & Irradiação solar $\left(\mathrm{W} / \mathrm{m}^{2}\right)$ & Temperatura $\left({ }^{\circ} \mathrm{C}\right)$ & Umidade $(\%)$ & Vento $(\mathrm{m} / \mathrm{s})$ \\
\hline Postura & $20-804$ & $11,8-26,7$ & $42-107$ & $0,0-8,2$ \\
Diapausa & $27-531$ & $11,0-24,0$ & $37-90$ & $0,0-9,3$ \\
\hline
\end{tabular}

A temperatura mínima registrada para o início das atividades de vôo de $P$. saiqui foi de $11^{\circ} \mathrm{C}$ (Tab. I). Entretanto, a partir de $21^{\circ} \mathrm{C}$ tornaram-se mais intensas (Fig. 4). HiláRIO et al. (2000) também observou a temperatura de $11^{\circ} \mathrm{C}$ para saída de $M$. bicolor bicolor. Diferentemente, a temperatura mínima para o vôo de $P$. emerina e $P$. remota foi de $16^{\circ} \mathrm{C}$ (KLEINERT-GIOVANINNI 1982; IMPERATRIZ-FONSECA et al. 1985). IWAMA (1977) e KLEINERT-GIOVANINNI \& IMPERATRIZ-FONSECA (1986) verificaram temperatura mínima para o vôo de $T$. angustula de $17^{\circ} \mathrm{C}$ e para M. marginata marginata de $14^{\circ} \mathrm{C}$. Entretanto, a temperatura mais elevada para o início das atividades de vôo, $18^{\circ} \mathrm{C}$, foi verificada para $T$. carbonaria na Austrália (HEARD \& HENDRIKZ 1993).

A temperatura mínima para o início das atividades de vôo parece variar de acordo com as condições das colônias. Com base nas atividades externas das abelhas, IMPERATRIZ-FONSECA et al. (1985) caracterizaram colônias de $P$. remota em fracas, médias e fortes. Constataram que a colônia forte iniciou as atividades de vôo antes que as demais. Além disso, estes autores sugerem que em espécies de Plebeia a variação da temperatura mínima para o início das atividades de vôo possa ser influenciada pelo tamanho do corpo da abelha. Segundo LACERDA et al. (1991), em colônias fracas o volume de alimento depositado na célula de cria é menor, mais diluído, o que ocasiona o surgimento de imagos menores. 


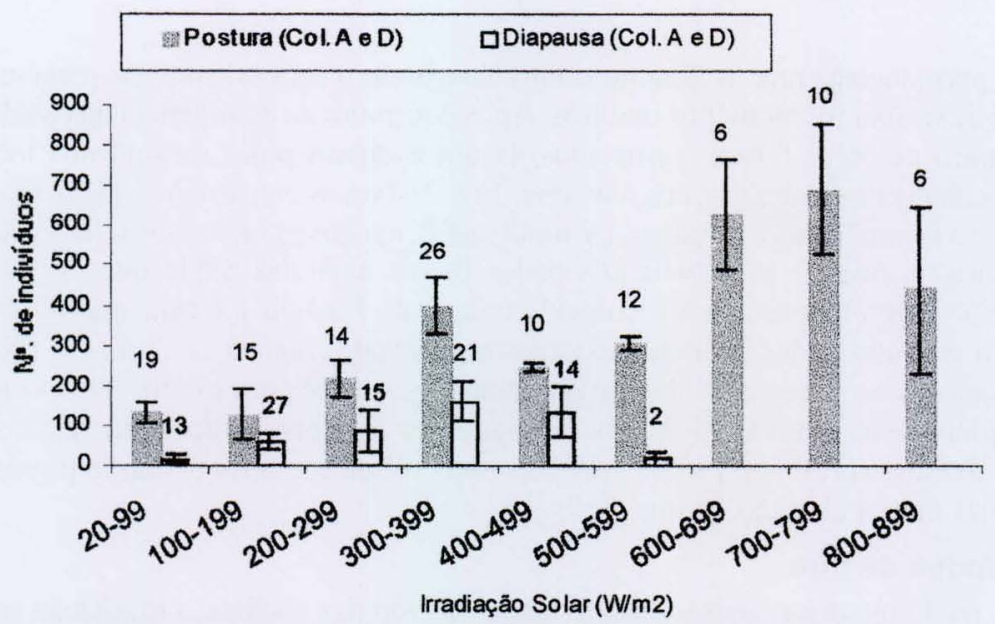

Fig. 3. Média e desvio padrão do número de indivíduos de duas colônias de $P$. saiqui que realizavam atividades de vôo em relação a irradiação solar, durante o período de postura e de diapausa; os números acima das colunas indicam o total de observações.

Além da temperatura limitante para o início das atividades externas HILÁRIO et al. 2000 referem a faixa de temperatura ótima para o vôo de 11 espécies de Meliponini. Em P. saiqui percebe-se (Fig. 4) que as maiores intensidades de vôo coincidiram com as temperaturas mais elevadas no período de diapausa.

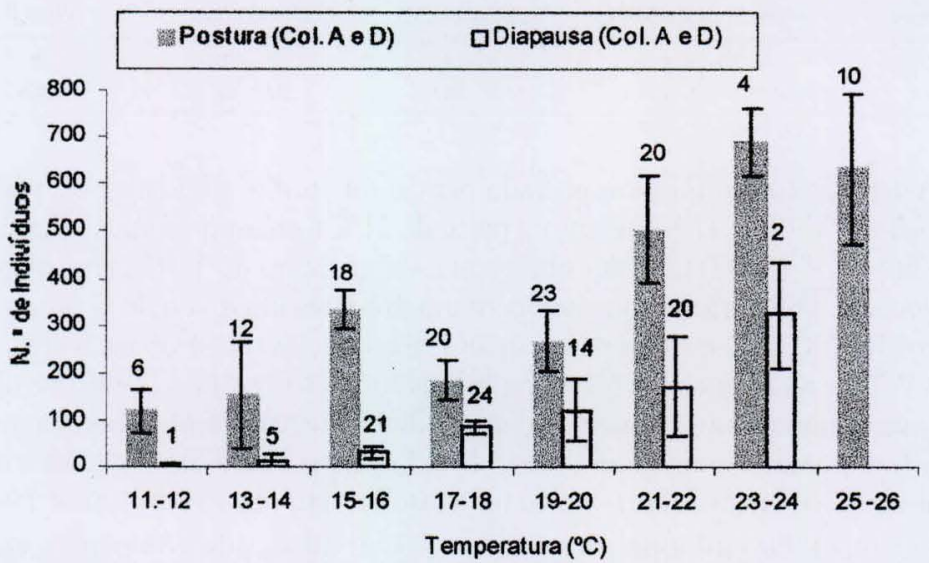

Fig. 4. Média e desvio padrão do número de indivíduos de duas colônias de $P$. saiqui que realizavam atividades de vôo em relação a temperatura, durante o período de postura e de diapausa; os números acima das colunas indicam o total de observações.

A maior intensidade de vôo de $P$. saiqui ocorreu entre 40 e $79 \%$ de umidade relativa (Fig. 5). Estes resultados aproximam-se aos obtidos para $P$. emerina, $M$. marginata marginata e $M$. marginata obscurior, com umidade relativa entre 40 a 70\% (KLEINERT-Giovaninni 1982; KLEINERT-GiovaninNi \& IMPERATRIZ-Fon- 
SECA 1986). Para $P$. remota, a maior intensidade de vôo observada foi sob umidade relativa de 60 a 84\% (IMPERATRIZ-FONSECA et al. 1985). A umidade relativa ótima para o trabalho externo de T. angustula foi de 30 a $70 \%$ (IwAMA 1977).

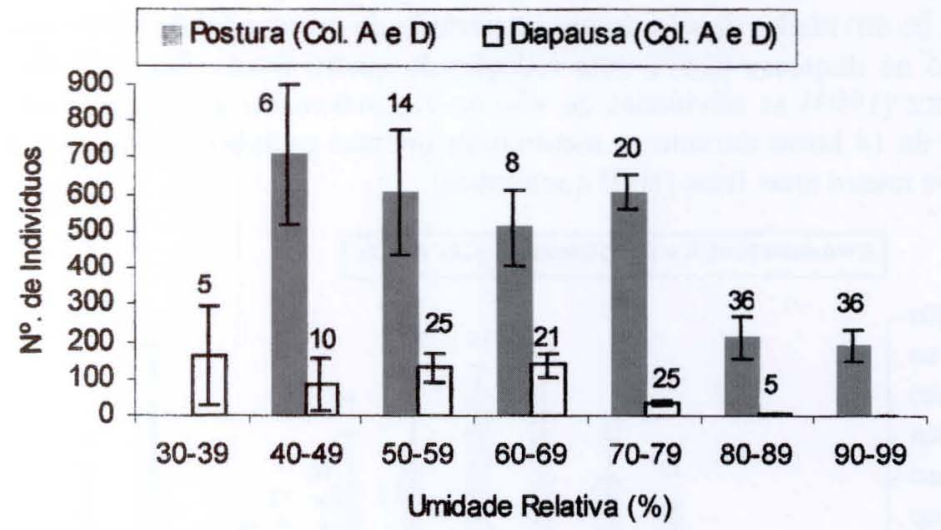

Fig. 5. Média e desvio padrão do número de indivíduos de duas colônias de $P$. saiqui que realizavam atividades de vôo em relação a umidade relativa, durante o período de postura e de diapausa; os números acima das colunas indicam o total de observações.

Em relação à influência do vento, observou-se atividade de vôo de $P$. saiqui em todos os valores registrados (Fig. 6). Ventos de 2 a $4 \mathrm{~m} / \mathrm{s}$ não restringiram as atividades de vôo de T. angustula (IWAMA 1977), assim como ventos de 4,9 m/s também não interromperam o vôo de T. carbonaria (HEARD \& HENDRIKZ 1993). KLEINERT-GIOVANINNI \& IMPERATRIZ-FONSECA (1986), verificaram que ocasionalmente ventos de $3 \mathrm{~m} / \mathrm{s}$ provocam diminuição das atividades externas em $M$. marginata marginata e M. marginata obscurior. Em contrapartida as atividades de vôo de $P$. emerina são restringidas com ventos de 4m/s (KLEINERT-GIOVANINNI 1982).

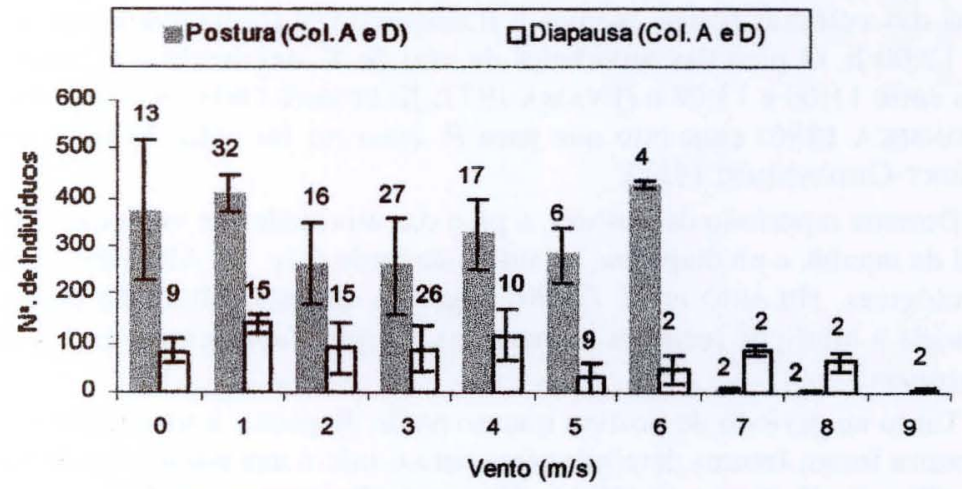

Fig. 6. Média e desvio padrão do número de indivíduos de duas colônias de $P$. saiqui que realizavam atividades de vôo em relação ao vento, durante o período de postura e de diapausa; os números acima das colunas indicam o total de observaçōes. 
A amplitude diária de vôo de $P$. saiqui, durante o período de postura, estendeu-se das 6:00 às 19:00 h, com maior intensidade entre 11:00 e 12:00 h. Na diapausa, a duração foi inferior, limitada entre 8:00 e 17:00 h. Neste período, o maior movimento externo ocorreu entre 13:00 e 14:00 h (Fig. 7). Assim, a amplitude máxima de atividades de vôo durante o período de postura foi de 13 horas diárias, enquanto na diapausa houve uma redução de quatro horas. Segundo HEARD \& HENDRIKZ (1993) as atividades de vôo de $T$. carbonaria atingiram a amplitude máxima de 14 horas durante os meses mais quentes (outubro a março) e de nove horas nos meses mais frios (abril a setembro).

\section{Postura (Col. A e D) 口Diapausa (Col. A e D)}

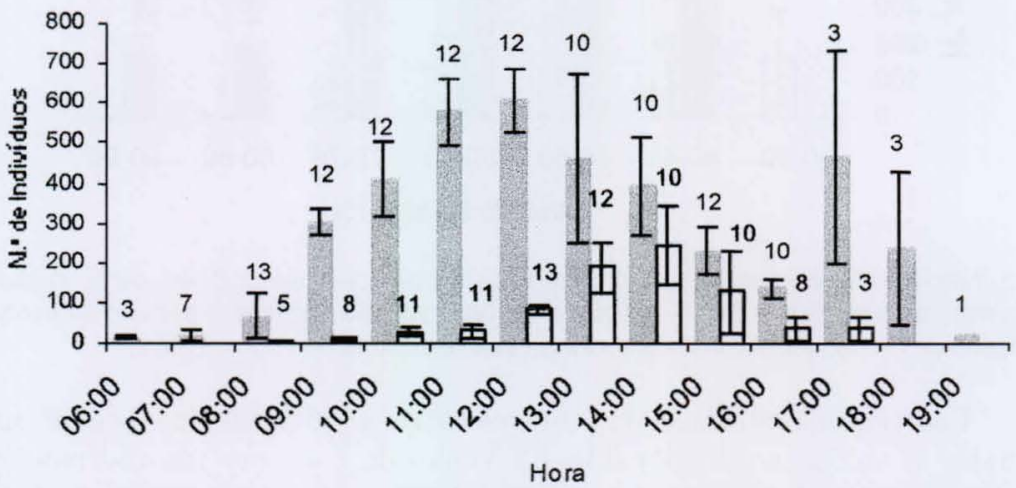

Fig. 7. Média e desvio padrão do número de individuos de duas colônias de $P$. saiqui que realizavam atividades de vôo em relação ao horário, durante o período de postura e de diapausa; os números acima das colunas indicam o total de observações.

No trabalho desenvolvido por HILÁRIO et al. (2000) com $M$. bicolor bicolor, a atividade de vôo foi elevada entre 8:00 e 12:00 h, e o pico das atividades externas das colônias fortes, médias e fracas ocorreu respectivamente às 8:00, 9:00 e 12:00 h. O pico das atividades de vôo de $T$. angustula e $M$. marginata ocorreu entre 11:00 e 13:00 h (IWAMA 1977; KLEINERT-GIOVANINNI \& IMPERATRIZ-FONSECA 1986) enquanto que para $P$. emerina foi entre 13:00 e 14:30 h (KLEINERT-GIOVANINNI 1982).

Durante o período de postura, o pico das atividades de vôo concentrou-se no final da manhã, e na diapausa, no início da tarde (Fig. 7). Além das variações meteorológicas, HILÁRIO et al. (2000) sugerem que essa alteração possa estar relacionada à oferta de recursos alimentares, os quais apresentam ciclos diários e/ou sazonais.

Tanto no período de postura quanto no de diapausa, a irradiação solar e a temperatura foram fatores determinantes para o início das atividades de vôo das abelhas (Figs 3 e 4). Em concordância, HEARD \& HENDRIKZ (1993), consideraram os fatores temperatura e irradiação solar determinantes para as atividades de vôo T. carbonaria. 
Nas tabelas II, III e IV verifica-se correlação positiva entre a atividade de vôo e os fatores meteorológicos irradiação solar e temperatura. Por outro lado, a correlação entre a atividade de vôo e a umidade relativa foi negativa. Desta forma, os dados obtidos indicam que o vôo das abelhas apresenta maior intensidade nas horas mais quentes e quando a umidade não é elevada.

Durante o período de postura, tanto nas análises de regressão simples (diária e sazonal), quanto na análise múltipla (sazonal), verificou-se que a influência da irradiação solar, temperatura e umidade relativa foi significativa nas atividades de vôo (Tabs II, III, IV e V).

Tabela II. Análise de regressão simples (valores diários), durante o período de postura da rainha, relacionando a influência dos fatores meteorológicos com as atividades de vôo de $P$. saiqui; coeficiente de correlação ( $r$ ); nivel de significância $(p)$, destacado em negrito $p<0,05$; entre parênteses a colônia analisada.

\begin{tabular}{|c|c|c|c|c|c|c|c|c|}
\hline \multirow{2}{*}{ Data } & \multicolumn{2}{|c|}{ Irradiação solar } & \multicolumn{2}{|c|}{ Temperatura } & \multicolumn{2}{|c|}{ Umidade relativa } & \multicolumn{2}{|c|}{ Vento } \\
\hline & $r$ & $p$ & $r$ & $p$ & $r$ & $\mathrm{p}$ & r & $p$ \\
\hline $09 / 10 / 98(\mathrm{~A})$ & 0,801 & 0 & 0,858 & $2,04 \times 10^{-5}$ & $-0,919$ & $4,64 \times 10^{-7}$ & $-0,149$ & 0,580 \\
\hline 09/10/98 (D) & 0,686 & 0,003 & 0,791 & 0 & $-0,839$ & $4,86 \times 10^{-5}$ & $-0,187$ & 0,487 \\
\hline $18 / 10 / 98(A)$ & 0,365 & 0,164 & 0,485 & 0,056 & $-0,639$ & 0,007 & $-0,106$ & 0,693 \\
\hline 18/10/98 (D) & 0,401 & 0,122 & 0,432 & 0,094 & $-0,653$ & 0,006 & $-0,147$ & 0,585 \\
\hline 19/11/98 (A) & 0,650 & 0,006 & 0,731 & 0,001 & $-0,750$ & 0 & $-0,230$ & 0,389 \\
\hline $19 / 11 / 98(D)$ & 0,559 & 0,024 & 0,685 & 0,003 & $-0,721$ & 0,001 & $-0,251$ & 0,347 \\
\hline $24 / 11 / 98(A)$ & 0,702 & 0,002 & 0,882 & $5,92 \times 10^{-6}$ & $-0,836$ & $5,36 \times 10^{-5}$ & 0,278 & 0,295 \\
\hline $24 / 11 / 98(D)$ & 0,805 & 0 & 0,857 & $2,15 \times 10^{-5}$ & $-0,836$ & $5,29 \times 10^{-5}$ & 0,370 & 0,157 \\
\hline $03 / 12 / 98(\mathrm{~A})$ & 0,893 & $3,04 \times 10^{-6}$ & 0,747 & 0 & $-0,895$ & $2,68 \times 10^{-6}$ & 0,021 & 0,936 \\
\hline $03 / 12 / 98$ (D) & 0,839 & $4,77 \times 10^{-5}$ & 0,701 & 0,002 & $-0,866$ & $1,4 \times 10^{-5}$ & $-0,070$ & 0,794 \\
\hline $21 / 12 / 98(\mathrm{~A})$ & 0,685 & 0,003 & 0,785 & 0 & $-0,562$ & 0,023 & $-0,184$ & 0,493 \\
\hline 21/12/98 (D) & 0,633 & 0,008 & 0,776 & 0 & $-0,534$ & 0,032 & $-0,324$ & 0,220 \\
\hline
\end{tabular}

Tabela III. Análise de regressão simples (valores diários) durante a diapausa, relacionando a influência dos fatores meteorológicos às atividades de vôo de $P$. saiqui; coeficiente de correlação (r); nivel de significância $(p)$, destacado em negrito $p<0,05$; entre parênteses a colônia analisada.

\begin{tabular}{|c|c|c|c|c|c|c|c|c|}
\hline \multirow{2}{*}{ Data } & \multicolumn{2}{|c|}{ Irradiação solar } & \multicolumn{2}{|c|}{ Temperatura } & \multicolumn{2}{|c|}{ Umidade relativa } & \multicolumn{2}{|c|}{ Vento } \\
\hline & $r$ & $\mathrm{p}$ & $r$ & $p$ & $r$ & $p$ & $r$ & $p$ \\
\hline $17 / 05 / 99(A)$ & 0,534 & 0,033 & 0,640 & 0,007 & $-0,491$ & 0,052 & $-0,247$ & 0,356 \\
\hline $17 / 05 / 99$ (D) & 0,650 & 0,006 & 0,659 & 0,005 & $-0,548$ & 0,027 & $-0,221$ & 0,409 \\
\hline $26 / 06 / 99$ (A) & 0,694 & 0,002 & 0,682 & 0,003 & $-0,326$ & 0,217 & 0,018 & 0,944 \\
\hline 26/06/99 (D) & 0,736 & 0,001 & 0,800 & 0 & $\cdot 0,383$ & 0,142 & 0,026 & 0,923 \\
\hline $28 / 06 / 99$ (A) & 0,835 & $5,57 \times 10^{-5}$ & 0,813 & 0 & $-0,325$ & 0,219 & 0,390 & 0,134 \\
\hline 28/06/99 (D) & 0,753 & 0 & 0,887 & $4,54 \times 10^{-6}$ & $-0,505$ & 0,045 & 0,300 & 0,258 \\
\hline $13 / 07 / 99$ (A) & 0,577 & 0,019 & 0,643 & 0,007 & $-0,440$ & 0,087 & $-0,229$ & 0,393 \\
\hline 13/07/99 (D) & 0,654 & 0,005 & 0,753 & 0 & $-0,539$ & 0,031 & $-0,126$ & 0,639 \\
\hline $28 / 07 / 99(A)$ & 0,321 & 0,224 & 0,614 & 0,011 & $-0,576$ & 0,019 & $-0,104$ & 0,699 \\
\hline 28/07/99 (D) & 0,461 & 0,072 & 0,788 & 0 & $-0,735$ & 0,001 & $-0,205$ & 0,445 \\
\hline
\end{tabular}


Tabela IV. Análise de regressão simples (sazonal), durante o período de postura e diapausa, relacionando a influência dos fatores meteorológicos com às atividades de vôo de $P$. saiqui; coeficiente de correlação (r); nível de significância ( $p$ ), destacado em negrito $p<0,05$; entre parênteses a colônia analisada.

\begin{tabular}{|c|c|c|c|c|c|c|c|c|}
\hline \multirow{2}{*}{ Data } & \multicolumn{2}{|c|}{ Irradiaçāo solar } & \multicolumn{2}{|c|}{ Temperatura } & \multicolumn{2}{|c|}{ Umidade relativa } & \multicolumn{2}{|c|}{ Vento } \\
\hline & $r$ & $p$ & $r$ & $\mathrm{p}$ & $r$ & $\mathrm{p}$ & $r$ & $p$ \\
\hline Postura (A) & 0,678 & $3,22 \times 10^{-14}$ & 0,625 & $9,98 \times 10^{-12}$ & $-0,690$ & $7,23 \times 10^{-15}$ & $-0,024$ & 0,812 \\
\hline Postura (D) & 0,623 & $1,21 \times 10^{-1} 1$ & 0,623 & $1,13 \times 10^{-11}$ & $-0,680$ & $2,52 \times 10^{-14}$ & 0,001 & 0,990 \\
\hline Diapausa (A) & 0,498 & $2,55 \times 10^{-6}$ & 0,489 & $4,15 \times 10^{-6}$ & $-0,194$ & 0,083 & $-0,102$ & 0,364 \\
\hline Diapausa (D) & 0,615 & $1,24 \times 10^{-9}$ & 0,681 & $3,48 \times 10^{-12}$ & $-0,383$ & 0,000452 & $-0,032$ & 0,775 \\
\hline
\end{tabular}

Durante o período de diapausa, a análise de regressão múltipla (sazonal) evidenciou que os fatores irradiação solar e temperatura influenciaram significativamente na atividade de vôo das abelhas (Tab. V). Esses dados corroboram os resultados obtidos na análise de regressão simples (diária e sazonal), exceto para a variável umidade relativa que foi distinta em ambas colônias. Na colônia $\mathrm{A}$, a umidade relativa não foi significativa exceto em 28/07/99, ao passo que na colônia $\mathrm{D}$ esse fator exerceu influência na maioria das vezes (Tab. III). Esse fato pode ser atribuído a diversos fatores, considerando-se que as colônias apresentam diferenças nas suas condições internas, a exemplo do número de indivíduos e do estoque de alimentos. Além disso, características intrínsecas (genéticas) poderiam estar relacionadas à tolerância a condições desfavoráveis.

Tabela V. Análise múltipla (sazonal), durante o periodo de postura e diapausa, relacionando a influência dos fatores meteorológicos às atividades de vôo de $P$. saiqui; nivel de significância (p), destacado em negrito $p<0,05$; entre parênteses a colônia analisada.

\begin{tabular}{|c|c|c|c|c|}
\hline \multirow{2}{*}{ Data } & Irradiação solar & Temperatura & Umidade relativa & Vento \\
\hline & $p$ & $\mathrm{p}$ & $\mathrm{p}$ & $\mathrm{p}$ \\
\hline Postura (A) & 0 & 0,004 & 0 & 0,546 \\
\hline Postura (D) & 0 & 0,004 & 0 & 0,745 \\
\hline Diapausa (A) & 0 & 0 & 0,559 & 0,655 \\
\hline Diapausa (D) & 0 & 0 & 0,642 & 0,503 \\
\hline
\end{tabular}

De modo semelhante, IWAMA (1977) observou que os fatores irradiação solar, temperatura e umidade influenciaram as atividades de vôo de T. angustula, nos meses de abril a agosto.

Durante os períodos de postura e de diapausa constatou-se, através das análises de regressão simples (diária e sazonal) e múltipla (sazonal), que o vento em nenhum momento influenciou significativamente as atividades de vôo das abelhas (Tabs II, III, IV, V e Fig. 6).

O período de diapausa variou nas quatro colônias. A colônia $\mathrm{C}$ entrou em diapausa no início do outono (março), enquanto as demais colônias, no final dessa estação (maio). O término da diapausa ocorreu durante o inverno, em julho na colônia D e em agosto nas colônias A, B e C (Fig. 8). 


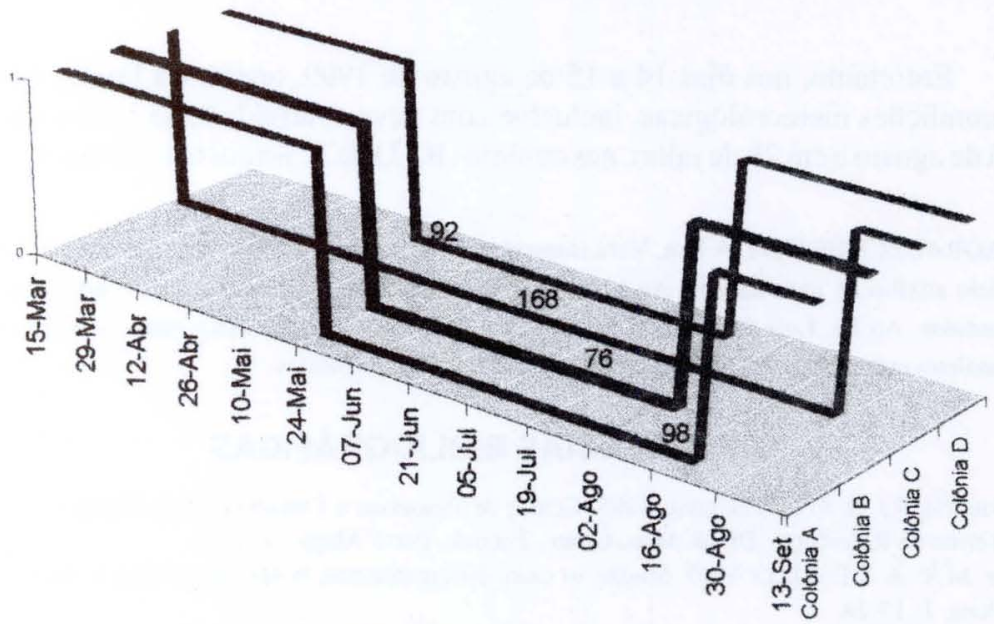

Fig. 8. Períodos de postura (1) e de diapausa ( 0 ) de quatro colônias de $P$. saiqui, observado de março a setembro de 1999.

Estudos realizados com Plebeia spp., que habitam em regiões frias, revelam que as colônias cessam a construção de células de cria e postura durante o outono, como verificado no presente trabalho (JULIANI 1967; TERADA 1972; VAN BENTHEM et al. 1995; FREITAS \& WITTMANN 1997). IMPERATRIZ-FONSECA \& Oliveira (1976), registraram que as colônias de $P$. saiqui bem como de $P$. emerina, $P$. droryana e $P$. remota apresentavam-se em diapausa durante o inverno. Entretanto, essas autoras não mencionam quando se inicia o período da diapausa, impossibilitando uma comparação entre as colônias mantidas em São Paulo e no Rio Grande do Sul.

O fato da colônia $\mathrm{C}$ iniciar a diapausa no começo do outono, sete semanas antes das demais colônias do estudo, resultando em um período mais longo em diapausa, sugere que algum fator interno da colônia tenha determinado a antecipação desse estado. Essa variação temporal no início da interrupção da construção das células de cria também foi observada em $P$. remota, sobre a qual registrou-se uma diferença de seis semanas entre colônias mantidas no mesmo local (VAN BENTHEM et al. 1995).

O período de diapausa das colônias estudadas de $P$. saiqui foi de 76, 92, 98 e 168 dias, respectivamente nas colônias B, D, A e C (2,5 a 5,6 meses). Registros da literatura indicam que colônias de $P$. emerina, $P$. saiqui, $P$. remota e $P$. droryana permanecem em diapausa durante aproximadamente 3 meses, no sul do Brasil (IMPERATRIZ-FONSECA \& OLIVEIRA 1976). VAN BENTHEM et al. (1995) observaram que em $P$. remota (São Paulo) a duração da diapausa variou de 2 a 4,5 meses.

IMPERATRIZ-FONSECA \& OLIVEIRA (1976) observaram que a diapausa pode ser influenciada pelas bruscas variações de temperatura e por fatores internos das colônias, a exemplo da substituição da rainha (VAN BENTHEM et al. 1995) ou, ainda, segundo IWAMA (1977), a diminuição da construção dos favos de cria em $T$. angustula estaria relacionada à quantidade de néctar e pólen no campo. 
Entretanto, nos dias 14 e 15 de agosto de 1999, apesar da brusca mudança das condições meteorológicas, inclusive com neve, a atividade de postura iniciada em 6 de agosto e em 26 de julho, nas colônias B e D de $P$. saiqui não foi interrompida.

\begin{abstract}
AGRADECIMENTOS. À Dra. Vera Imperatriz-Fonseca (USP) e Dra. Márcia Ribeiro (USP) pelo auxílio na metodologia. Ao MSc. Sérgio Hilário (USP) pelas sugestōes e bibliografias cedidas. Ao Dr. Luiz Glock (PUCRS) e MSc. Walter Castro (PUCRS), pela orientação nas análises estatísticas. À CAPES por ter concedido bolsa de estudos.
\end{abstract}

\title{
REFERÊNCIAS BIBLIOGRÁFICAS
}

Bertoletti, J.J. \& M.B. Teixeira. 1995. Centro de Pesquisas e Conservação da Natureza Pró-Mata. Termo de Referência. Divul. Mus. Ciênc. Tecnol., Porto Alegre, 2: 1-47.

BRIAN, M.V. \& A.F. KELLY.1967. Studies of caste differentiantion in Myrmica rubra L. Insectes Soc. Paris, 1: 13-24.

Denlinger, D.L. 1986. Dormancy in tropical insects. Annu. Rev. Entomol. 31: 239-264.

Freitas, S.W. \& D. Wittmann. 1997. Poligenia temporária em Plebeia wittmanni Moure \& Camargo, 1989 (Hymenoptera: Apidae, Meliponinae). Biociências, Porto Alegre, 5 (2): 61-69.

GILBERT, W.M. 1973. Foraging behavior of Trigona fulviventris in Costa Rica (Hymenoptera, Apidae). Pan-Pac. Entomol., San Francisco, 49: 21-25.

HEARD, T.A. \& J.K. HENDRIKZ. 1993. Factors influencing flight activity of colonies of the stingless bee Trigona carbonaria (Hymenoptera: Apidae). Aust. Jour. Zool. 41: 343-353.

HILÁRIO, S.D.; V.L. IMPERATRIZ-FONSECA \& A.M.P. KLEINERT. 2000. Flight activity and colony strength in the stingless bee Melipona bicolor bicolor (Apidae, Meliponinae). Rev. Brasil. Biol., Rio de Janeiro 60 (2): 299-306.

IBGE. 1986. Levantamento de Recursos Naturais. Rio de Janeiro, IBGE, Vol. 33, 796p.

ImPERATRIZ-FonseCA, V.L. \& M.A.C. Oliveira. 1976. Observations on a queenless colony of Plebeia saiqui (Friese) (Hymenoptera, Apidae, Meliponinae). Bol. Zool., São Paulo, 1: 299-312.

IMPERATRIZ-FonseCA, V.L.; A. KLEINERT-Giovannini \& J.T. PiReS. 1985. Climate variations influence on the flight activity of Plebeia remota Holmberg (Hymenoptera, Apidae, Meliponinae). Revta bras. Ent. 29 (3/4): 427-434.

Iwama, S. 1977. A influência de fatores climáticos na atividade externa de Tetragonisca angustula (Apidae, Meliponinae). Bol. Zool., São Paulo, 2: 189-201.

Juliani, L. 1967. A descrição do ninho e alguns dados biológicos sobre a abelha Plebeia julianii Moure, 1962 (Hymenoptera, Apidae). Revta bras. Ent. 12: 31-58.

KEFUSS, J.A. 1978. Influence of photoperiod on the behaviour and brood-rearing activities of honeybees in a flight room. Jour. Apic. Res., London, 17: 137-151.

KLeINERT-GIOVANNINI, A. \& V.L. IMPERATRIZ-FonSECA. 1986. Flight activity and responses to climatic conditions of two subspecies of Melipona marginata Lepeletier (Apidae, Meliponinae). Jour. Apic. Res., London, 25 (1): 3-8.

KLeinert-GIovannini, A. 1982. The influence of climatic factors on flight activity of Plebeia emerina Friese (Hymenoptera, Apidae, Meliponinae) in winter. Revta bras. Ent. 26 (1): 1-13.

LACERDA, L.M.; R. ZuCCHI \& F.S. ZuCOLOTO. 1991. Colony condition and bionomic alterations in Geotrigona inusitata (Apidae, Meliponinae). Acta Biol. Par., Curitiba, 20 (1,2,3,4): 109-123.

LeATHER, S.R.; K.F.A. WALTERS \& J.S. BALE. 1993. The ecology of insect overwintering. Cambridge, Univ. Press, 255p.

Michener, C.D. 2000. The bees of the world. Baltimore, Johns Hopkins Univ. Press, 913p.

NeChols, J.R; M.J. TAuber; C.A. TAUber \& S. MASAKI. 1999. Adaptations to hazardous seasonal conditions: dormancy, migration and polyphenism, p. 159-200. In: C.B. HufFaker \& A.P. Gutierrez (Eds). Ecological Entomology. New York, John Wiley \& Sons, $2^{\text {nd }}$ ed., 756p. 
Nogueira-Neto, P. 1997. Vida e criação de abelhas indígenas sem ferrão. São Paulo, Nogueirapis, $445 \mathrm{p}$.

OliveirA, M.A.C. 1973. Um método para avaliação das atividades de vôo em Plebeia saiqui (Friese) (Hymenoptera, Meliponinae). Bol. Zool. Biol. Mar., N. Ser., São Paulo, 30: 625-631.

Pirani, J.R. \& M. Cortopassi-Laurino (Eds). 1993. Flores e abelhas de São Paulo. São Paulo, Editora Univ. São Paulo, $2^{\mathrm{a}}$ ed., 192p.

TAuber, M.J. \& C.A. TAUber. 1976. Insect seasonality: diapause maintenance, termination e posdiapause development. Annu. Rev. Entomol. 21: 81-107.

Terada, Y. 1972. Curvas de sobrevivência em operárias de Plebeia droryana (Hymenoptera, Meliponini). Cien. Cult., São Paulo, 24 (6): 343-344.

VAn Benthem, F.D.J.; V.L. Imperatriz-FonseCa \& H.H.W. Velthuis. 1995. Biology of the stingless bee Plebeia remota (Holmberg). Observations and evolutionary implications. Insectes Soc., Paris, 42: 71-87.

VAN LAERE, O.V. 1971. Influencia de algunos factores en el reposo invernal de las colonias de abejas. Apiacta, Bucarest, 6 (2): 55-58.

Wilms, W; L. Lutz; A. Zillikens; B. Blochtein \& W. Engels. 1997. Bees and other insects recorded on flowering trees in a subtropical Araucaria Florest in southern Brazil. Stud. Neotrop. Fauna Environ. 32: 220-226.

Wittmann, D. \& M. Hoffmann. 1990. Bees of Rio Grande do Sul, southern Brazil (Insecta, Hymenoptera, Apoidea). Iheringia, Ser. Zool., Porto Alegre, (70): 17-43.

Recebido em 25.V.2001; aceito em 03.IX.2002. 